\title{
Streets into Stages: an interview with Surveillance Camera Players' Bill Brown.
}

\author{
Erich W. Sc hienke ${ }^{1}$ and Bill Brown?
}

\begin{abstract}
The Surveillance Camera Players, from New York City, are a performance based activist-awareness group who openly, critically, and playfully engage various elements of public surveillance. This discussion with Bill Brown, co-founder of the Surveillance Camera Players, covers the group's history, the strategy of their public performances and, during the winter months, their weekly walking camera tours. Furthermore, Brown critiques the growth of the surveillance society and how it continues to reify a culture of public conformity and increasingly enforces a dangerous homogeneity of behavioral display across our social ecologies.
\end{abstract}

\section{Introduction}

Drawing a good deal of political and methodological inspiration from the Situationists, the Surveillance Camera Players (SCP) are urban surveillance 'activists', yet they are not protesting any specific policy. They are performers, but they do not consider themselves artists. They pose no physical threat, but make the authorities noticeably nervous. On the other hand, SCP are themselves nervous because of what they perceive to be a failure in the public to openly recognize what is at stake in the growth of the surveillance society.

Drawing from Foucault (2001) in his description of the Greek parrhesiastes (person possessing 'free speech') provides us with insight into the role the Surveillance Camera Players (SCP) and Bill Brown, as its defining force, are playing in the open criticism of public surveillance. As Foucault re-folds the concept, he describes parrhesia as "a kind of verbal activity where the speaker has a specific relation to the truth through frankness, a certain relationship to his own life through danger, a certain type of relation to himself or other people through criticism (self-criticism or criticism of other people), and a specific relation to moral law through freedom and duty. More precisely, parrhesia, is a verbal activity in which a speaker expresses his person relationship to the truth, and risks his life because he recognizes truth-telling as a duty to improve or help other people (as well as himself). In parrhesia, the speaker uses his freedom and chooses frankness instead of

\footnotetext{
${ }^{1}$ Rensselaer Polytechnic Institute, New York, USA. mailto:schiee@ @pi.edu

${ }^{2}$ For specific information on the Surveillance Camera Players and for some useful resources go to http://www.notbored.org/the-scp.html
} 
persuasion, truth instead of falsehood or silence, the risk of death instead of life and security, criticism instead of flattery, and moral duty instead of self-interest and moral apathy." (Foucault, 2001: 19) Using Foucault's description of parrhesia to qualify the actions of the SCP and Bill Brown is intended to paint them, not as the usual 'nutter' scopic paranoids that some in the press take them fore, but as frank truth-sayers who gently and humorously remind us that the rampant growth of public surveillance, as a socio-technical cybernetic feedback loop going awry, is something we should be uneasy with and feel nauseated about. In taking what is ultimately an incalculable risk with the authorities, Brown puts himself fulltime to the task of learning (with Ph.D. research skills) everything he can about the limits of surveillance and disseminating that knowledge back out to the public in various forms, thus he lays everything about his life on this line. I will leave it up to the reader, however, to tease out the details and decide whether or not the parrhesiastes analysis of Brown and the SCP is one that holds throughout.

\section{Inteniew}

The form of this interview follows how the discussion unfolded, as a sort of Situationist derive of its own. The discussion took place in a coffee house a few blocks from Washington Square Park, in New York City. About a dozen of us had just finished a walking tour given by Bill of surveillance cameras installed in and near the parameter of the park $^{3}$. Since the discussion was ongoing, there are a few questions from others from the tour. The transcription will enter the discussion here with us sitting down in a coffee house.

Bill Brown: You raised a bunch of my buzzword buttons with mentioning the Flaneur, and tour guides... it was very interesting. Especially because I've been re-reading Benjamin's comments on the Flaneur and they are highly critical. He's not a stroller in the way the Surrealists were strollers. He's very critical of Flaneurs.

Architect: Well yes, the Situationists were too. The idea of the Derive is not this aimless wandering, but a very directed, purposeful walk.

Erich Schienke: Like De Certeau?

A: Yeah, then De Certeau after that.

BB: I've seen it alluded to, but I haven't seen it actually proved in images. Which is overlapping the Lettrists' derives [with] where the barricades were placed in May 1968. Is there an overlap between the places they discovered and the places they decided to put barricades?

\footnotetext{
${ }^{3}$ A movie of the tour can be accessed here: http://www.surveillance-and-society.org/articles1(3)/SCP.mp4
} 
A: I'm going to save my questions for another tour. I'm going to be doing any number of tours and I will be visiting each more than once, so I will catch you another time.

BB: Before you go...your interest is in the tours and how they can be unpredictable. Today's tour nothing awry took place. There was the one guy that wandered by and said something and I like those moments, because there was no heckling the tour. The tour is almost built for hecklers. People come in and you explain to help convince... The tours that are best to go on are those where something is going to happen.

Bob DeMarco: What sorts of things have happened?

BB: Before Sept. $11^{\text {th }}$ on the tour of city hall, a police officer came up to the tour and asked us what we were doing and led it for five minutes. He explained some of the security devices. He said, 'Did you know about that camera for example?" and pointed across Broadway about 200 feet up. Sure enough there was a camera there. Said things like, did you know there are some windows set up with certain vibration sensitive machines that can hear a conversation you were having if you were to walk past it.

ES: For example, you can do that with a laser reflected off of a window.

BB: It was remarkable. But that was pre-Sept. $11^{\text {th }}$. Now they won't come out. They won't acknowledge that we're here. The City Hall tour there is sometimes the potential for things to happen. Cops will sometimes shadow the tour. Frankly, I am shocked the FBI hasn't visited the tours. Or asked me to discuss my relationship with any terrorists groups. It's shocking because [the FBI] are all over the website. DOJ and...

ES: I’ve read your BLOGs. (http://www.notbored.org/army.html) Amazing.

BB: They're not fucking around, those people visiting. That's not a Private on his lunch hour. They've probably been kicking it around their various lawyers saying "is there an obscure section of the Patriot Act where we can actually charge this guy?" Well they said, our lawyers, (special Air Force and Naval special criminal investigations units) each are saying "no." Then they'll wonder what the FBI boys think about it and they'll visit the site for a while. They've all come to the decision that until this country stops being a democracy, they can't charge activity like this. Until they come out with the Patriot Act II, such is being designed now, then they may say specifically that the disclosure of security measures is itself a security violation. When we go on the United Nations tour, you can't photograph any part of First Avenue and that the times I was there with students, I would say to these students "Put your cameras away!" This one woman heard this as a reason to pull her camera out and stood on top of a ledge and is filming. Like that (with a snap) a Federal officer armed guard was there asking the magic words... 'Did you just film my building?!" And the answer is always, "no." If you say yes, I assume that's grounds for interrogation. I interceding and explained no she hadn't. I pulled him aside and said, 'This is a student and I just warned her about this." I don't want some 19 year-old with a sense of privilege fucking up my life. 
ES: Yeah. Yeah.

BB: I know the risks I'm taking, but does she know the risks? Just because she's white and in the U.S. If she were another color, or from another country like Yemen... it could be a very different interaction. A friend of mine is a BBC documentary maker and the FBI just called him up to say "you were reported taking pictures of a pharmaceutical building in New Jersey. So, this isn't left-wing paranoia anymore. It's just the keeping track of what these people are doing. That's why on these walking tours at some of these places, it's good to push the boundary a little and see if the guard will come over.

ES: So, perhaps you could tell me about how the Security Camera Players... oops, sorry the Surveillance Camera Players began. That was in '95-'96?

BB: Interesting mistake. Security camera is an interesting phrase that I've always avoided because nobody is opposed to security, but surveillance has a touched a raw nerve quality about it. So, I've never used "security cameras" because it's poetically not just. Surveillance Camera Players formed in November of 1996 as a Situationist prank without the historical or social basis. It happened because a friend of mine who shared an interest in the Situationists would go into places like this, if there was a camera there and he would hand out a flyer called the guerilla programming of video surveillance equipment. It had a geat many brilliant suggestions about what one might do about the cameras. I looked at one that suggested a group could form that would treat the surveillance cameras as if they were television cameras and, say, offer programming every Thursday night at nine o'clock. So, I focused on that and gave it the name Surveillance Camera Players. The two groups of friends, this guy that wrote the pamphlet and his friends, and my group of friends collaborated on the first performance that we did together December $10^{\text {th }}$ of '96.

ES: Was that the performance of $U b u$ Roi?

BB: Yes, the police came five acts into a seven-act play and shut it down totally. This was when the police were very, very brusque and clear about what their purposes were. The cop walked up to me and his first words were to me "I've already warned you once..." So what he was signaling to me was that if this goes anywhere in some sort of legal process, I will lie on the stand and claim, just as I did, that I warned you once to get out of here and that you disregarded me and therefore I was within my rights to handcuff and pepper-spray you because you resisted. But we pleaded with him saying, in the next scene the bear gets killed. So, there is a guy with a bear mask taped around his face. Not a smile came to the cops face and he said, "No, get out of here." And that was such a success from the Situationists perspective on pranks. The danger of pranks is that you are ignored. Especially if you are doing something as avant-garde as $U b u$ Roi on the $100^{\text {th }}$ anniversary of its first performance. The danger of such obscurity is that it never comes out of obscurity. This got such an incredible response that we didn't perform for a year and a half. Then came the events that I alluded to on the walking tour, which was the Giuliani (then mayor of NYC), Saphir (then Police commissioner of NYC) initiative. So, suddenly a group that had no future, that was just a prank to amuse jaded intellectuals, 
suddenly had a context which was the police (re)installing surveillance cameras. So, we performed again in July 1998 in answer to the rise of the Washington Square Park cameras.

ES: How did you choose cameras? "How do you say, ok, we're going to perform in front of this camera."

BB: You could perform, if there are 2,937 cameras, in 2,937 places. Because we're a small group we are always thinking about what will offer the maximum amount of punch. The play, the time it's going to be performed, and the location. Often, those decisions as to the location, play, and day are hooked into each other. So, sometimes one decision will make another. For example, we found a chunk of the Berlin wall watched by surveillance cameras on $52^{\text {nd }}$ Street. That itself made a bunch of decisions for us. Such as, to perform there on the $10^{\text {th }}$ Anniversary of the Berlin Wall coming down, which was November $9^{\text {th }}$ 1999. We performed Wilhelm Reich's The Mass Psychology of Fascism, which was produced a few month's earlier. Each one of those decisions would pull the factors in. They tend to be highly coded locations. The more coded it is, the less explanation we need to do to people who run into us. If there are surveillance cameras at a church, we pick the biggest church in Manhattan-St. Patrick's Cathedral—so the maximum amount of punch can be delivered. It would be done on Easter Sunday, therefore. So, these are interconnected decisions.

ES: So, it's part of the theater?

BB: Here theater is a very interesting word because the surveillance cameras are attempting to stage a theater of conformity, so that even before artists or Situationists arrived to see the dramatic potential, they're already turning the streets into stages and people perform either by ignoring the cameras, or they know that they're there and perform in conformity with societal norms. So, what we do is attempt to meddle with the theater they have already established - a theater of performing non-conformity and resentment. A sense of protest. So, we don't bring theater to the cameras, it's already a part of their set-up. Even though they're camera, you would think it would be videophotography-film that would be called into play first. Because these cameras have a very specific social positioning, it is theater they call upon before any other art form.

ES: What is a performance like? What do you have $\mathrm{t}$ reduce to get it across the surveillance camera? How do you have to reduce and codify it in a way that gets across it in a silent medium?

BB: What we've done is, number one, all sound has to be excluded because the cameras don't pick up sound. Even though recent court cases, for example there was a guy who recently won a multi-million dollar settlement against a hotel in West Virginia because it turned out that the surveillance cameras were mic'd as well. We assume that cameras aren't picking up sound because that's the law. It's the Federal law (Title 3 of the Federal Crime Statutes). So, the reduction, first of all, is that everything must be silent. Which, inadvertently puts the group right into the thick of some very interesting Avant-Garde 
theatrical movements of the $20^{\text {th }}$ Century. Primarily Artaud, who wanted to have a silent, or non-verbal theater that is called upon by the cameras. Then, the play that must be chosen must have, as it were, a totally transparent relationship to the cameras. The plays that we started out doing were opaque. The relationship to Jarre or Becket or Poe, to the surveillance cameras was not clear. So, we jettisoned any play that wasn't specifically referring to the cameras because it took up valuable time in explaining it, so that ultimately meant that once we scripted George Orwell's 1984 the only place to go there after was scripting our own plays. In addition, the signboards always show an icon of a surveillance camera so that people never have any doubt whatsoever about what we're doing. The camera is on the boards and we're pointing them at a camera. That gets around the problem of most Avant-Garde art, which is that it is really there to be explained, not experienced. It's to be footnoted in the index to find when you're reading the primary material. We've gotten rid of all potential for footnotes or bibliographies. It's just simply to be delivered and understood on the spot.

ES: What's you're background? Are you an 'Avant-Garde' artist?

BB: I've been politically ultra- left since I was 13 . My parents we McGovern Democrats.

ES: You're from New York City?

BB: Yes. So, I was a McGovern Democrat since I was 13 and have gotten increasingly extreme since then. So, I went from ultra-left in the Democratic Party, through Marxism, through the Situationists, straight into Noise.

Bob: I have a question about the plays. Do you primarily play to the camera and do you have people watching or taping. Or is it a performance you give to an audience that all gather near the camera?

BB: Excellent question. And I recently changed my mind on it yet again. The original conceit, and it is a powerful conceit, which is why I've vacillated back and forth, is that it is very boring to be a video camera watcher. Some of the more honest watchers will say, you look at empty elevators and corridors for hours. So, the conceit was that I it boring to be a watcher, therefore we'll give them something to watch. The further joke was, when they watch anything, they watch sex and violence-so, we'll give them literature and class. Then, as the group became covered and actually began to be reach people it seemed the real focus switched to the people that wandered by actually seeing the staging of this strange spectacle. We began playing to them, because ultimately we're not going to convince the camera operator to smash his or her equipment and join us on this side. But, we're trying to work directly on the populous to inform them and agitate them. So, then we consciously work to the audience as bystanders. Recently I realized, going back again, in part because of the degree of web hits, the obviously the real serious watchers in this society - the National Imagery and Mapping Agency (NIMA), the NSA, the CIA — that they're paying attention lets me know that our ultimate audience are still the watchers. It seems to be... why decide one way or the other? It's obviously a productive dialectic to say that it is both of them. Especially because the one thing security culture thrives upon 
is secrecy. Secrecy is its oxygen. If you talk about it you're introducing carbon-monoxide into its oxygen and hopefully we can have it choke on being talked about.

ES: What was your education?

BB: I have a Ph.D. in American Literature. I was taught by Leslie Fiedler, who just died recently. Leslie Fiedler was a specialist at showing that literature is not necessarily in a book. That it can be Star Trek, to see its movement in terms of cultural forms. Then, I taught at the Rhode Island School of Design (RISDI) on how to make literature comprehensible to the art students. That has to be done always through visual things, musical things, sculptural forms, so I developed a series of thought patterns on how to reach people that involved the arts. That was all, in many ways, preparation for the Surveillance Camera Players. So, I have a dual background in art and politics. I think I mentioned earlier that at the end of the day I see what I'm doing as political with artistic relevance, but it's not primarily to be understood as art. I think that would not have as much of a future - art sort of restricts your future, or shows that recuperation is an inevitable problem that you'll have to deal with. Or, that I would ever eventually be separated off from the network and be made a star. But, if it's politics (not art) then the network goes on without stars and there's less danger of recuperation. It's harder to recuperate politics than art.

ES: How did you become and expert on surveillance cameras? How have you trained yourself?

BB: The walking tours have made it necessary. As someone who has taught, I felt a great burden to relay accurate information. So, I spent years working on what I now realize are the E-Z Pass readers (note: from the tour these readers are mounted on the tops of buildings in lower-Manhattan at points where there was no toll collection, there is an explanation in the video.) Years working on it. Working Google very hard. Reading everything I can on the subject. So, I spend hours a day using Google news or search engines, things that push to me various stories, read it all and keep a variety of files which I can search through and say "oh, this made reference to this various wireless technology, didn't I read about Proxim before?" Then, I can look it up and co-ordinate it. Research skills help me teach myself about this to the point where I'm getting to be an expert in this field. I'm not sure many people in the security industry know as much as I do about cameras because I spend so much time now focusing on it with Ph.D. research skills.

ES: Have you cataloged a lot of this information to make it more accessible to others?

BB: I started a project of making an encyclopedia of surveillance terms and I see upstream from Surveillance and Society that someone is planning that. So, I did entries for helicopters, spy planes, un-inhabited aerial vehicles-a whole series of things condensing this research and also always focusing on their weaknesses and vulnerabilities. In part because I want to suggest technology is never a useful item in solving problems relating to fear, psychology, safety. 


\section{ES: Politics.}

BB: It's politics. Those problems with wireless technology (mentioned on the tour) emphasize that these need human solutions, not technological ones.

ES: Sure, sure. So, the Players have worked with many people in other countries?

BB: In funny ways. If you want to give it a bad spin, we're sectarian. If you want to give it a good spin, we prize our autonomy. So, that means like the Situationists, that we don't just admit anybody into the group. We don't want to have a big group in which lots of people join. The idea is just a proliferation of independent groups who have the name in common. But when we have gone to other countries intending to plant seeds that would sprout-we've been to Germany, Holland, England, Spain, and Austria-to varying degrees those fertilization efforts have been successful. England was totally unsuccessful. The English have given up. The most vocal of the people we have spoken to have said, "this is a dead issue here mate. It has been over and done with here for years. It's too late. We've moved on to other issues." In Bologna Italy an SCP group took root there immediately and has been growing strong ever since. So, these tours have a variety of degrees of strengths. It's interesting that we can't seem to plant a group in San Francisco. We actually went out there and met with a few who seemed interested, performed with them, gave them the plays, and it went nowhere.

ES: Things have a tendency to do that in San Francisco.

BB: It was very noticeable it wasn't going anywhere. In part I think it's the sunshine.

ES: Some people say it's the Feng Shui of the city itself. Since it's surrounded by water on so many sides, things never get finished... they just sort of float there in the fog.

BB: Also, I think the police are not as much of a terror there as they are here. This is a police related matter, and if the police aren't shooting people 41 times or raping them in bathroom stalls, the community isn't as ready to be arrested in the thousands as they are here when something like that happens. So, it's a reading of their feeling towards the police. It's also sunny, and the marijuana is wonderful. There are a variety of reasons for not becoming involved. I will ne ver forget when I went out there once being a hard-core Velvet Underground New York guy and going out to San Francisco I smoked a joint up in the Berkeley hills looking out over the ocean... and it occurred to me... flower power finally made sense to me, whereas before I couldn't get it. Flower power... there's no soil in New York. And it finally occurred to me.

ES: The bridge, the bay, the view...

BB: And I got it. That's why it doesn't make any sense here in New York.

ES: What are some of the other localizations of difference you have seen, say in Italy or perhaps England? 
BB: This is easy. The Germans have taken to us incredibly strongly. The French as well. We toured 10 cities in Germany without any problem. We can tour 10 cities in France without any problem. There is a proliferating series of groups. It's interesting in part those are the two countries actively resisting the Bush-Rumsfeld doctrine in Iraq. They are countries who have had a firsthand experience with fascism. Italy too. One of the reasons I think that Americans are slow to get to certain subjects, and I include surveillance among them, is that if you look at the anarchists sites or the ultra-leftist sites here, very few of them are paying attention to surveillance. They're mostly interested in the World Bank, the WTO, the IMF, commodity corporation issues. They're very slow on the uptake about State Fascism. I think the reason is the country's lack of historical experience with fascism. So that in Germany, Italy, and France, you talk about surveillance cameras and they think about the Stasi, the KGB, and Mao's Red Guard right out of the box. Where here, people are confused... they don't know what is at stake.

ES: The same could be said of a lot of different issues...

Bob: I'm sure plenty of people that have walked by your tours, have the reaction that this is some sort of paranoid conspiracy kind of guy talking about cameras. I think people are jump on that side of things.

BB: They psychologize.

Bob: It's also not a pleasant thing to think about.

BB: Fortunately, in that way, I am one of the rare activists who can say, thanks to Sept. $11^{\text {th }}$ it is now impossible to call me paranoid. It got to be a theme in media's criticisms, "ah, he's paranoid." And my delusion would be that think I see surveillance cameras everywhere. Now, nobody makes that judgment ever again. In that way it's a typical pattern. Thirty years ago, what was a left-wing conspiracy theory about JFK being shot, is now accepted fact. That's what Sept. $11^{\text {th }}$ did for my group. It has totally killed this thing that I'm paranoid and feeding off the future. I'm struggling to keep up with the present and I often used to flip it back on people and say, "no, the people who are paranoid are the ones putting up the cameras. What I'm doing is struggling to remain un-paranoid."

ES: As Pynchon wrote, "you hide, they seek." So, how have your thoughts on this topic changed over time? What are some of the plateaus you've reached in terms of your observations and general attitude towards surveillance?

BB: It's too general of a question, but I can answer it in that generality which is, this began with no future, whereas my motto now is that this has an unlimited future. It's dizzying when I realize, that since August of 1999, I've been interviewed almost every single day. So that what has changed is simply the idea that this is a real thing and that this is not going to go away. So, I guess that is what has changed, the attitude that this is just a little thing I'm doing and my life is elsewhere. The change is that, if I want it to be, this could be my life's work. In some ways I hate the metaphor, but it's interesting, which 
is as far as intellectual capital goes, I got in really early on that surveillance stock and that I'm going to make a fortune as an activist...

ES: ....in cultural capital...

BB: ... fighting against it because it's now the future of what society is like. When we started that was not something I thought of at all. That would be the biggest change, it's very serious, it's almost like a vehicle that's been built which we can now drive someplace instead of saying it's just a prank, it's a fragment.

ES: How are you getting funding?

BB: There is no funding. This requires just money for the mail, the post-office box, and the webhosting — that's it.

ES: What else do you work on?

BB: Nothing. Technically, I've been unemployed for almost two years. So, I live in the margins of the economy. I get the lowest amount of un-employment insurance the state can pay. This has become a full time job. That's amazing. When you compare this to other issues, other groups, other pranks, you'd think that the risk of any of these things is that you are ignored. It's amazing to me that every time I answer my email I get an email or voicemail that there is someone else who is interested in it. It's like a dream I can't wake-up from, but it's a perverse dream because it shows that this society is changing for the worse, very quickly and very rapidly. There is this Lenny Bruce joke about how he, J. Edgar Hoover, and Jonah Salk, thrive on ignorance, disease, and violence. And if the messiah came and got rid of everything, that they would be out of a job. It's the same thing, I exist is a parasitical relationship to the worse aspects of the society. So, when I thrive, it's bad for society as a whole. Ironically it's better if groups like this don't thrive.

Bob: Have you been interrogated by police or any sort of Federal authority?

BB: On the way to Toronto, the cops went through the entire car. They watched the video tapes and said, what's all this about surveillance cameras? Then they let me go. So, there's been no interrogation. That's why, given what's happened on the website, I'm surprised. I think that the answer is that they know, the next day after they interrogate me I'll call Ron Cuby and Stanley Cohen and we'll have a big 'ole news conference.

ES: You mentioned in some of the writings, that "guerilla programming is the production of an action and not the consumption of a product."

BB: Actually, it was Michael who wrote that. So, it's not on the tip of my tongue what every sentence says. So, I need to be reminded of what you're saying...

ES: Well, I'm wondering how you are thinking about the cultural capital you are producing and how it's meant to be consumed? 
BB: That's what's interesting. I actually disagree with some of the presuppositions of that very piece, which is that apparently the largest ring you reach of control is the commodity, that the Commodity is controlling everything and not the State. I disagree. I think that the Commodity is in service of the State, and the State is not in service of the Commodity. So, I have larger disagreements with that piece, but to answer the question of who is consuming what the SCP produces, that if it enters into the realm of culture we run the risk of being consumed as yet another cool, or weird item. It's something people can be entertained by, or maybe slightly educated by it, but they can put it aside as just another entertainment. So, that if the focus remains on the State, then it's much harder to say this is 'cool'. This can't so easily be consumed as counter-culture, because it really isn't culture. I think those were some of the things Michael was wrestling with in that text, is how do you go about performing in front of the cameras without becoming just another actor on stage.

ES: Have you ever gotten any of your tapes back from any of the surveillance sources?

BB: Yes. I have a big stick that I have invented that keeps working, which is that if somebody doesn't give me a video cassette on the thing that I have worked so hard producing for them, I have a thing called the 'dead-ends' page on the website and I put their name there and say I worked for however many hours for this person and they couldn't be bothered to send me a tape. A year later they will be searching through Google for their name and will find this. They'll call me and say, "hey, that's not fair. The piece aired and everybody loved it." I'll say, "you never told me that it aired, you never sent me the video copy. Can I have one now?" Otherwise they can run what they want to run, and never get back to you. They will say that it run when it never did. Say that it ran well, and it looked good when they made me look like a paranoid fool. The only way to get back to them is not to write letters to their editor or leave messages with their secretary, but to put them on the pages because reporters are vain.

ES: Funny technique. I was wondering though about the surveillance tapes.

BB: I sort of told a different story there. No, the camera operators will never admit that they're taping. Therefore, they can't have tapes to give you. We've never really asked. So, the times that we get tape off of the monitors or want to see what the performances looked like, we staged it ourselves. So, we would set you up (referring to Bob as camera man) in front of a monitor displaying from a police camera in the subways. There are cameras near the token booths you can perform in front of. That's how we got our most famous videotape of George Orwell's 1984 at the end of '98 and the police showed up during the room 101 torture scene and speak on camera, and the thing plays out as if it were scripted. Those tapes can be really useful, and it's because of that I think the cops no longer come anywhere near us because we're mic' $d$ and have cameras and that they'll end up as some part of a newscast feature if they come near us.

ES: How often are you doing performances? 
BB: They average once a month. They're very informal.

ES: Impromptu?

BB: Not quite impromptu, because there will usually be a week's notice to the performers. But, they're not as regularized as the walking tours. Which is good for me because I can continue to operate at this level without being frustrated at my friends who don't want to do this every single week. Whereas I would do this every single day.

Bob: You would perform everyday?

BB: I do something related to this every single day. There are other people who are interested in this, but their not as obsessional as I am.

Bob: Do you list your performances anywhere? Or is it just on your website?

BB: In advance, never. Because when we listed in advance I would get a telephone call from the intelligence division of the police saying, "hi, we're the intelligence division of the police. We read that you're going to be at City Hall tomorrow. What do you plan on doing?" And I'd find that intimidating. And also, they show up in force. So, when we publicized this one performance on December $14^{\text {th }}$ of 2000 , I was the only performer in front of the webcam, and there were 14 police officers who showed up. Uniforms, detectives, plain clothesmen, cars, a whole panoply of cops for one performer. I wasn't very please with that.

Bob: Did you do the performance or did they stop you from doing it?

BB: No, I did the performance because I looked at them like... "you're kidding??!! Right?! You're here for me?" I shrugged and said this is preposterous. The guy in the car shrugged back at me as if to say, "this is just my job." Since Sun Tzu says the element of surprise is a very good force, especially for outmanned armies, we now use the element of surprise whenever possible.

Bob: The sniper on the roof fell asleep... (chuckles...)

BB: That also means we stay away from big demonstrations too.

ES: That makes sense.

BB: Yeah, because in a big demo where they are preemptively arresting anyone they want to, I don't want them saying, "oh, this is our opportunity to fuck with these guys, finally, who have made us look stupid. Let's just arrest them and put them through the system just to fuck with 'em." I wouldn't mind that because I've been arrested a number of times in New York and I know what to expect. I don't want to expose the other members of the group to it unless they're reading for it. You have to be well dressed if you're going to be arrested, because, it's freezing in there. So, I come to the walking 
tours, for example, over-dressed thinking I'm not just dressing for this weather. I'm thinking if they decide today's the day they're going to fuck with me, I'm wearing three layers of clothing. You need to be able to keep warm and to take something off to use as a pillow to sleep for all those hours you're waiting around in the tombs. So, we stay away from demos so we don't have to go through that.

ES: What about some of the other players? How do they learn about this and come to take part?

BB: They're almost all women.

ES: All women? Really?

BB: Which is interesting, yes. Typically when you see pictures of the performance, there's me, the white male talking head, then there are all these women, including my girlfriend Susan, who is a co-founder. I'd say the group has been $60-90 \%$ female through its entire existence. I think the reason is that most protests are stereotypically maleloud, angry, testosterone driven, using your voice loudly for angry chants. It's a kind of a biological cliché, nevertheless, they don't necessarily have the ability to be angry loud, so they prefer this kind of performance because they are able to express themselves without getting hung-up in the typical male stereotypes. Usually, for example in the protest against the war coming up next week, there will be protesters matched against police forces. The police forces will probably have, literally, hard-ons to arrest people. That's something no thinking woman wants to expose herself to unnecessarily. Especially given the salacious lies the police are told about what protestors are like. Therefore, women don't want to have much to do with the protest. Therefore, if we devise a form of protest where the police are not there because we surprise them, it's just us in the mass of people, then women come back into the fold. It's a very noticeable aspect.

ES: Very revealing I would say.

BB: Yes, it's very revealing. Because in all my time in political discussions, typically there's a loudmouth man who would dominate everything.

ES: What about children and the SPC? I know you've worked with them a bit, you were mentioning the Mylar balloons and the kids before (on the tour). Also, in reference to the discussion of wireless child surveillance cams in the homes whose transmissions can be picked up by anyone with a similar receiver.

BB: Yeah, seems like very cliché ground somehow, but yeah, the women and children. In England we had a couple of beautiful experiences where children on bicycles would find out what we were doing, then bicycle up ahead, spot the cameras for us and bicycle back to say, "oh, you should go this way." There are some great pictures of us performing in Germany, where at one of the performance in Mannheim a group of children who are gypsies, of Romanian origin, were there pointing out the cameras. This has been a loaded issue, especially since I wrote an article titled What About the Children? Because, most 
people will say, no matter what the issue is, "but, what about the children?" As if we have to dumb down or infantilize the whole population to make sure the children are safe, instead of raising the children to the level of adults. So, I suggest to reduce that, when people say, "what about the children?" I'll say the chances of a child being protected by a surveillance camera is much less. The real chance is not that the real pervert is not going to be watched by the camera operator, but that pervert is the camera operator who, with impunity, could stare at little Johnny or Josephine to his hearts content. That the danger is the watcher, not the 'bad man over there who the angel is going to keep us safe from.' I know this is the truth because those two 8 year-old girls I brought to Washington Square Park, when they found out there were cameras in the Park, they were furious. Apparently they went screaming back to their teachers saying, "you brought a bunch of kids to a park where they can watch us with cameras? You just helped make us possible victim to voyeurism and child molesters." I think that's much more accurate, is that in a hyper repressed society such as our, the places people with problems go are into being priests or the boy scouts, these are people who go there knowing that that's where they'll have access to children.

Bob: Who made that complaint?

BB: These two eight year-old kids. Incredibly smart kids and they obviously had liberal parents. They said, "the teacher bought a whole class to Washington Square Park without saying, 'you're being watched!" They're parents were obviously adult enough to say, there are men or women out there who don't have your best interests in mind. They have motivations you won't understand, but they want to invade your privacy. As adults we realize, yes, a guy in a booth who is bored, he's the one who's going to think he can get away with it. The idea there's some pervert stalking the street waiting to grab children is obviously a fiction. The same argument works for women and rape. Cynical people will usually say, typically men, we need the cameras to keep women safe from rapists, when it's more likely that if there's a rape that the camera operator is going to watch. Or, that there is a concept of video rape. That you can be raped all at once, or that you can be raped by a thousand small assaults known as video voyeurism.

ES: A great example of this, near my hometown, was when they were trying to get a police levy put through that was doomed to fail. Then, literally, 200 yards outside the police station there was an attempted rape (in a town where it very rarely happens because people aren't pedestrians) that was heavily publicized. Then the police levy goes through, no problem. It was probably one of the cops' buddies. The woman didn't get hurt.

BB: It might not be something even as evil as that, but cops who have access to data banks are routinely busted because they run somebody's name through the registry for a friend. They do it because they're ex-wife is now seeing some guy and they want to intimidate the new boyfriend. So they run them through criminal investigation, their license plate, use the cameras to watch them. Put a transponder under their car, not for security purposes, but just to know who their ex-wife is seeing. 
ES: The tool itself is supposed to disable that... but it only further enables and allows for it.

BB: It allows for it. That's right.

ES: It's not like the users have any ethical training or testing around is sues of voyeurism.

BB: That's really the nub here. Which is, no best practices, no privacy guidelines, no courses, no oversight mechanism, no enforcement that puts teeth on someone who is reviewed and felt to have violated protocol with the cameras. None of this is in place. So that it's not that we are dealing with things that are illegal. This is a lawless area, especially in America there are no laws covering these subjects. Only in the last few months have people realized this. Specifically when it comes to the fact that there is such a thing where people will put video cameras in gym bags to try to shoot up women's skirts to try to create sexually repressed images. Several State governments have realized that there is no law on the books that forbids this. One of the judges in the State of Washington stated that this is heinous behavior and that we frown on it, but it's not illegal because women have no right of privacy in public places. That obviously shows that it's not to encourage further invasions, but that the law have to be updated by several decades worth of effort to say that people do have the right of privacy and that they can't be indiscriminately video taped... in the same way that they can't be indiscriminately be audio taped.

ES: One of the arguments I've talked about with the Institute for Applied Autonomy, is the argument for putting cameras in a public space, is, in a sense, the move to privatize that space. So, the moment you've put a security camera into a public space, you've actually privatized that place. Regardless of whether it is being monitored by a State agency, or a private business, we lose the anonymity and open quality of a public space.

BB: I agree, but just as long we understand that this isn't just a strategy only of the corporate sector. When we hear the word "privatization" we almost always think of it in terms of private companies taking on the functions that used to be public, as if it's purely a corporate phenomena. So, I would agree provided that we register that privatization could also be a strategy of governing. It isn't simply a way to give goodies over to the private sector and bankrupting the government. The government has something to gain from the destruction of public spaces that may not be financial, but that it makes the public easier to control. So, it is a strategy of both the corporate entities as well as the government. To enrich upon it more-privatization as a term in that way catches both of those senses-privatization is privatizing government functions and having them run by corporations. But, it is also teaching people to stay in their own private lives, to no longer have a political awareness, in a sense, that your private life is always a public life. So, privatization is a turn away from public life towards the private as well. It's mimicked by governmental functions, but the functions continue to exist, even though police have become privatized, the plaza has become privatized, the government still very much exists. 
ES: Yeah, instead of becoming a 'police state', it's becoming a 'security guard state'.

BB: Right, it's becoming a security guard state. Because in police states, typical totalitarian powers, there has to be places for massive rallies. The Italian Fascists, the German Fascists, they all wanted a mass rally grounds so that people could express their solidarity by appearing in huge architectural formations of masses. In our society, which is a privatized one that is still totalitarian. It's still Fascist, but in isolated individuals who never rally in big massive crowds.

ES: It's interesting. For a radio show I was doing last Fall I went back and read over the air, Bataille's Mass Psychology of Fascism. I read one bit a week over the air. Does this not sound familiar people? Is there not something going on here?

BB: He's very useful. Writings from certain periods can be useful. I recently read the Accursed Share Volume 1, and was horrified to see it used as a frank justification for the Stalinist purges and the collectivization of the farms. It was the most brazen apology for Stalin that I've ever read. So, yes, Bataille is interesting, but apparently sometime in the 1940's he became rather corrupted. Mass Psychology of Fascism, and the Mass Expenditure of Excess, and those essays were from the 30's.

ES: Yeah, '27 and on.

BB: So, you have to choose your Bataille carefully. But yes, I found that essay very, very helpful.

ES: What would you like to say to the audience of the journal Surveillance \& Society?

BB: Ok, one may appear more relevant that the other. First is that we're told, this would be the purpose of focusing on this group to begin with, number one is that there is no political opposition to surveillance. For example, in England this is commonplace. "Give it up mate, there are too many years and it's too late for this." The purpose of Surveillance \& Society focusing on this group is that we're not lawyers, we're not academics, we're not teaching classes, or arguing for the institution of legislation. So that there are private individuals who are unaffiliated with these institutions who are against surveillance. That's number one. Number two is that resistance to surveillance isn't always among the artists or the left-wing intellectuals but one of the things I'm keeping track of on the website are high school students and workers who go on wildcat strikes when they find out their schools or factories are surveilled. The wildcat strike is significant to me because they are not going through labor, collective bargaining or complaining to the union. These are construction workers specifically in Nova Scotia and Australia; if they see a camera they go on a wildcat strike that afternoon. It's important to show the breadth of this resistance to surveillance as it already exists. Because too many times I'll read someone like Jeffery Rosen, who writes for the New York Times, a very sophisticated writer, can't find anybody who can articulate his arguments other than him-lots of theoretical objections to surveillance. He can't find anybody who can enunciate them for him. As if to say, this is all in a law professors head, on the ground 
that there are no activists. I find that again and again. So, not only are there people who can connect these intellectual critiques of surveillance to activists, and they're not only activists, they're artists, workers, students, the classic profile of people who have 'brought such troubles to the society 40 years ago.' You bring high schoolers and workers together in a general strike, and you've got a problem.

ES: Because you're setting up different conditions of a culture of the future with that threat as a possibility.

BB: The culture of the future and also that's the balance of May 1968, where 2/3 of France can walk out on a general strike. So that I'm, in that way, very optimistic despite the fact that a great deal is changing everyday to the worse. That it's easy to become full of despair. I couldn't do this unless I had the fundamental belief that this movement rises and has demonstrable points of growth. I'm not just saying that to puff up our own accomplishments - there are many other people involved. That's what I would want the readers to know, is that this movement is just beginning but it has deep roots.

ES: Is there any way of getting out of the binary opposition between the surveyor and the surveyed? Is there another position we could occupy? I see that in some ways you are playing that role. You're trying to exist as this boundary object that obviously acknowledges the fact that you are being surveyed-acknowledging the watcher. But it seems like there is another argument or position one could take. I'm not sure what it is, but somehow it would get our thinking beyond just that binary opposition of watcherwatched?

BB: I resist it, even though I think binary oppositions obviously might suggest simplicity. But, I've tried to keep that an opposition nevertheless because there are too many artists who want to play detective. They want to have it both ways. They want to be against surveillance culture, but they want to get dressed up in detective clothes and secretly take photographs. There is a lot of this crap. These artists are basically saying, "when I grow up I want to be a real detective." But since I'm a child, I'm going to play detective. Julia Scher is the worst offender here. So, she'll dress up in security guard outfit and she'll surveil people coming to the gallery, as if to say, "it isn't black and white. That at times we're surveilled or are the surveiller. Lighten- up there is an intermediary ground." Where as a political activist I want to make the ground between the two as thick as possible between the two. In some ways one of my enemies are people who want to blur the boundaries in the opposition, because ultimately I believe that some people are opposed to the cameras and some people aren't. And I, as a politically rhetorical person, have to say I am opposed to them and I don't want them even if it's going to assure me assure me of a career as a performance artist in galleries. Because, that what it communicates. That Julia Scher needs the cameras to continue her artistic career, and I don't. I'll go on to something else. I'd be more than happy to. But she'd say that's her bread and butter. So yes, I don't want to get out of that binary opposition, even though I recognize the validity of it being a binary opposition, I think there is, in many ways, too much hemming of the line. 
ES: It is useful. I'm just trying to think here... I mean if we can't yank all of the cameras in existence, and if it looks like there are only going to be more and more cameras then how can we creatively work around?

BB: I've got answers of course. Which is a gradual collapsing back to the human scale. Surveillance cameras are a specialized outgrowth of a police department. The police department are themselves a specialized outgrowth of the community as a whole. So that you could say it is possible to be unconditionally opposed to the cameras by saying, "I not only want to get rid of the cameras, I want to get rid of the police departments themselves." Replace both by communities who watch themselves. So this very much rhymes with whether or not you believe in direct democracy or representative democracy, which in many ways the police are the representative democracy, the governance. You can still have governance, it would be self-governance politically, as well as in communities the police come right from the community instead of being an artificial prosthesis, in the same way that the cameras are an artificial prosthesis jutting out of the police. Get rid of them both. I can site examples where this would work. For instance, I'm on the subway I can see very plainly there is a guy sitting next to a child whose mother is not paying attention, and this guy is definitely positioning himself to grab this girl's hand. A police officer is not on the train. There could be 25 cameras in there but it's going to be too late because he's going to grab that girl and go. I am able to look at her and say, get your child away from him, and that I save the child. Then go back to being a normal society member. I don't need to have a badge or a gun or an ego or anything. It's utopian, but it's also believable. It rhymes with existing political rhetoric, which, especially in New York, the police don't have residency requirements. They come in from Staten Island where they live in all white communities. They're told that blacks live like pigs. That they hate the police. No wonder they're shooting them all... they don't live in these areas. The cameras come from outer space in the same way.

ES: The big problem is that it's a community from outside the community that's doing the surveillance. If it was internal, it would make more coherent sense. That produces a huge untenable cultural difference.

BB: Exactly. So, if we want to stop crime what we do is start educating people to watch out for each other. Deeper still is ourselves. There is a psychological structure to it too, which is whether one is an adult or not, I have preserved in my head the infantilized relationship I had with my father. So that now, if that's not solved in myself I grow up believing in the big brother or big father. As a child, I'm afraid of taking care of myself, therefore daddy has to take care of me. Daddy, when I grow up, becomes the police, the army, the mayor. So, deeper still I have to look out to take care of myself and I don't need any police officer to take care of myself for me. So, it isn't just the communities maturing, it's individuals maturing as well. I say that knowing what I'm talking about, because as recently as when I was 25 this city scared the shit out of me and I couldn't bring my girlfriends here, I couldn't take my wallet out because someone would come and steal my wallet. I realized that if that's what I believed then that's what all these people believe, which is why they want a cop on the beat and a camera and an army. Get rid of this internal infantilization and we don't even need armies. 
ES: It's a lot cheaper.

BB: Well, that would be the answer. That's the largest issue, that in some ways the people that want more cops, more guns, more cameras are expressing the poverty of their own poor personal psychology and the bankrupt psychology of their social grouping, which can't defend itself.

ES: Morally bankrupt.

BB: And this really sings. You go up and say this in story in Harlem and they love it. It fits right into what they're thinking, which is that "this is our community and you don't need a white cop from Staten Island coming up to the South Bronx to shoot our children. They don't hear this as a flight of utopian imagining, this is very real for them.

ES: I wanted to try make that Harlem trek, but it was too cold for my camera that day.

BB: It was terrific. It was great. The reason that I've answered this way is when we went to Italy - this is what the roots of producing the mass psychology of fascism werepeople would say, "you're focusing on external things if you're focusing on the cameras. You've got to talk about god, father, the state-the typical authoritarian line-up of patriarchal power. To stop surveillance you've got to dig deeper into the relationship with children.

ES: It's interesting, going back to the Ten Commandments, the only one that's actually reflexive is "Thou shall not covet." Everything else is based on behavior and external actions. But that's the only one that refers to self-monitoring out of any of them. Out of ten, you only have one that you are the judge of.

BB: That's very interesting. It's like the Sermon on the Mount where Jesus says that there's a difference... everyone experiences lust in their heart... this is what got Carter into so much trouble... that there is a difference between acting on it and feeling it. Another way of answering the critique of surveillance is that everybody has something to be afraid of, something to hide, that it isn't just those criminals who are "bad". In some ways you have the cops survey those criminals over there in order to keep the criminal inside yourself in prison, never to break loose.

\section{References}

Foucault, M. and J. Pearson (2001) Fearless Speech. Los Angeles, CA: Semiotext(e), Distributed by MIT Press. 